
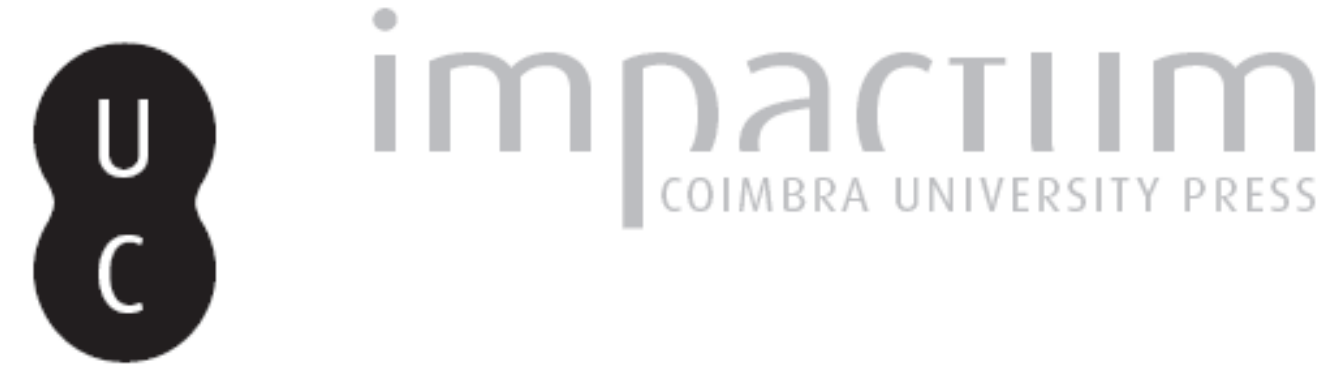

\title{
[Recensão a] Valeria Tocco, A Lira Destemperada. Estudos sobre a tradição manuscrita de "Os Lusíadas"
}

\author{
Autor(es): $\quad$ Almeida, Isabel
}

Publicado por: Imprensa da Universidade de Coimbra

URL

persistente:

URI:http://hdl.handle.net/10316.2/42707

DOI:

DOI:https://doi.org/10.14195/0870-8584_1_17

Accessed : $\quad$ 26-Apr-2023 12:18:38

A navegação consulta e descarregamento dos títulos inseridos nas Bibliotecas Digitais UC Digitalis, UC Pombalina e UC Impactum, pressupõem a aceitação plena e sem reservas dos Termos e Condições de Uso destas Bibliotecas Digitais, disponíveis em https://digitalis.uc.pt/pt-pt/termos.

Conforme exposto nos referidos Termos e Condições de Uso, o descarregamento de títulos de acesso restrito requer uma licença válida de autorização devendo o utilizador aceder ao(s) documento(s) a partir de um endereço de IP da instituição detentora da supramencionada licença.

Ao utilizador é apenas permitido o descarregamento para uso pessoal, pelo que o emprego do(s) título(s) descarregado(s) para outro fim, designadamente comercial, carece de autorização do respetivo autor ou editor da obra.

Na medida em que todas as obras da UC Digitalis se encontram protegidas pelo Código do Direito de Autor e Direitos Conexos e demais legislação aplicável, toda a cópia, parcial ou total, deste documento, nos casos em que é legalmente admitida, deverá conter ou fazer-se acompanhar por este aviso.

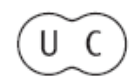




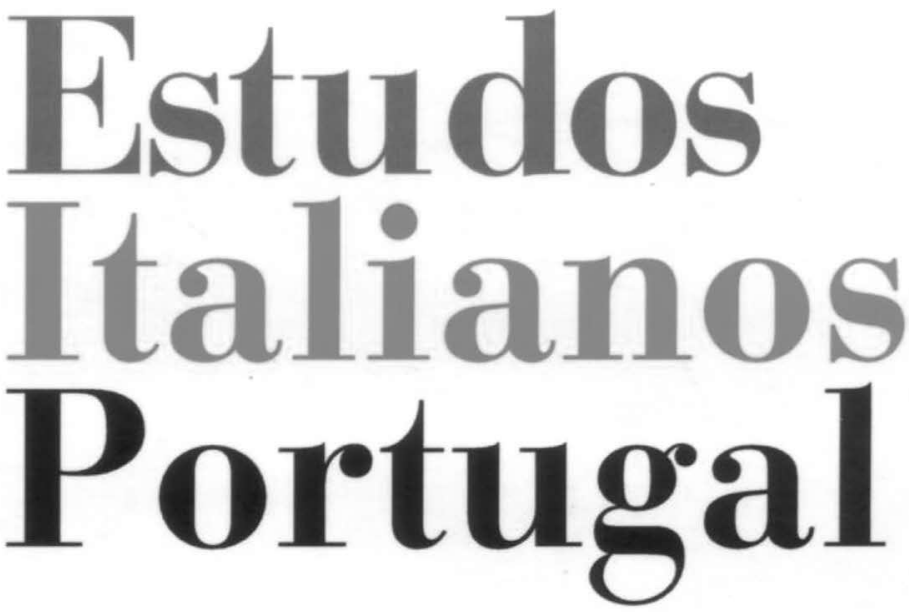

Instituto

Italiano

de Cultura

em Portugal

Nova Série

$\mathbf{N}^{\circ} \mathbf{1}$

2006 
vamente, ao neolachmannismo (de que esta obra representa a primeira descrição orgânica), à filologia dos textos impressos e à filologia dos textos modernos. Estes são os capítulos mais extensos e pormenorizados, nos quais os autores conseguem a não fácil tarefa de alcançar um perfeito equilíbrio entre o rigor da informação científica, uma linguagem acessível e uma leitura fácil.

A segunda parte do volume apresenta, por sua vez, tal como o seu título reza, exercícios de crítica textual: trata-se de um conjunto de textos que visa dar exemplos práticos de crítica textual e que ao mesmo tempo torna concretas as problemáticas de carácter teórico abordadas na primeira parte do volume. E, parece-me, é nesta segunda parte que reside a sua maior novidade. Apesar de ser, da mesma feita, o mais completo manual de crítica textual publicado em Português, os autores não deixam de apresentar estudos de sua autoria, nos quais, com a profundidade e a segurança de quem domina plenamente a área das ciências filológicas, aplicam nas suas várias vertentes os critérios teóricos apresentados na primeira parte do volume.
Os textos contidos nesta segunda parte são, como afirmam os autores, um conjunto de trabalhos, alguns dos quais inéditos, que pretendem ser exemplos práticos de aplicação das metodologias e temáticas apresentadas nos capítulos anteriores. Centram-me maioritariamente na produção de Martin Codax e de Luís de Camões, mas estão também presentes textos sobre Gregório de Matos (os sonetos), de Camilo Pessanha e de Fernando Pessoa.

O primeiro dos três ensaios reservados a Luís de Camões, de autoria de Maurizio Perugi, centra-se sobre a lírica de $\mathrm{Ca}$ mões e os métodos da moderna crítica textual. Nas suas páginas, esse crítico apresenta uma explicitação prática de todos os elementos inovadores desta nova corrente de estudos filológicos. Defende a importância da análise de um texto e das suas variantes (do próprio autor ou da tradição), tendo em consideração um conjunto de factores que, embora autónomos entre si, levam a uma análise, mais ampla e mais fiel, dos textos em questão: é na conjugação deste conjunto de factores - factores dinâmicos (dependentes da variação diacrónica e diatópica da tradição escrita bem como da sua difusão), factores prosódicos, métricos, sintácticos e lexicais - que reside a grande novidade metodológica que os autores assumem como um dos mais importantes progressos nos estudos filológicos.

Através deste volume, o leitor, independentemente do seu grau de familiarização com a crítica textual, tem acesso a um manual de referência relativamente a questões teóricas, bem como a um conjunto de ensaios que exemplificam e consubstanciam o tipo de análise que se pode efectuar de um texto literário. Sem dúvida que este Fundamentos da Crítica Textual elaborado por Barbara Spaggiari e Maurizio Perugi representa um óptimo instrumento de trabalho não só para especialistas da área dos estudos filológicos, mas também para estudantes que se dedicam às ciências filológicas. LINO MIONI

Valeria Tocco, A Lira Destemperada. Estudos sobre a tradição manuscrita de "Os Lusíadas", Bari, Adriatica Editrice, 2005,
135 pp. [incluindo bibliografia e aparato das variantes].

Devem-se a Valeria Tocco, entre outros trabalhos, edições das Obras Poéticas de Diogo Brandão, das Poesias e Sentenças de D. Francisco de Portugal, $1 .^{\circ}$ Conde de Vimioso, ou da Jornada às Cortes do Parnaso, de Diogo de Sousa: interesses vários mas convergentes na dedicação às letras portuguesas e sempre cultivados de acordo com a rigorosa formação filológica da autora, docente da Universidade de Pisa e colaboradora da Scuola Normale Superiore no âmbito do projecto de investigação "Rapporti e scambi letterari tra Italia e Penisola Iberica nel Rinascimento e Barocco". É, pois, numa fecunda linha de estudos de crítica textual que se insere o novo volume publicado na Biblioteca di Lusitania: A Lira Destemperada. Sobre a tradição manuscrita de Os Lusíadas.

Como frisa Valeria Tocco, o trânsito de versões da epopeia, durante o tempo, aliás longo, da sua génese, nada surpreende face aos usos quinhentistas: com ou sem permissão de Camões, múltiplas cópias terão circulado, reflectindo estádios diversos da 
composição do poema. E mesmo depois de impresso o texto, não cessaria por inteiro a sua reprodução manuscrita: também esta prática se enquadra nos hábitos culturais do século XVI e, ainda, da centúria seguinte. $O$ que se torna dificil - adverte a autora é destrinçar, na tradição acessível, toda apógrafa, o que será camoniano e o que provém de mão alheia (entenda-se: transformações - ora deliberadas ora involuntárias - ocorridas no processo de transcrição, ou intervenções radicalmente apócrifas). Não espanta, assim, a prudência que rege a construção deste ensaio, nem o relevo que nele assume a arte de conjecturar. E porque é terreno sinuoso o que se explora, mais avulta a exigência lógica e a clareza do itinerário que se giza e cumpre.

Começa a investigadora por repertoriar os dados disponíveis, distinguindo quatro conjuntos de testemunhos de versões manuscritas (completas ou parciais) do poema épico: o dos testemunhos quinhentistas que sobreviveram e que podem ser hoje compulsados (é o caso, singular, do Cancioneiro de Luís Franco Correia); o dos testemunhos só indirecta- mente conhecidos (v.g., as versões que pertenceram a Pedro Coelho e a Manuel Correia de Montenegro, registadas por Manuel de Faria e Sousa nos seus Comentários a Os Lusíadas, estampados em 1639); o dos testemunhos "virtuais" (existentes, segundo palavra fidedigna, mas fechados à consulta pública como o manuscrito "judaizante" sob custódia de Maria Antonieta Soares de Azevedo); o dos testemunhos perdidos (no rol, a cópia executada por encomenda do Conde de Vimioso, na altura do regresso de Camões a Lisboa, vindo do Oriente). Deixando de parte, por óbvias razões, estes dois últimos conjuntos, Valeria Tocco centra a sua atenção no texto guardado no Cancioneiro de Luís Franco Correia (uma cópia do canto I) e na informação (declaradamente arbitrária) veiculada por Manuel de Faria e Sousa acerca das versões d' Os Lusíadas transmitidas por Coelho (cantos I-VI) e por Montenegro (cantos I-X). A meta da pesquisa é nítida: ao reunir as oitavas difundidas na tradição manuscrita (ou quanto sobre elas é viável apurar), leva-se a cabo a colação desses "restos duma primeira versão do poema ou das várias fases de elaboração do mesmo" (p. 14) com a editio princeps; e, salientando as variantes, ilumina-se a história desta corrente textual e seu valor para uma melhor compreensão da aventura criativa de Camões.

Meticulosamente, apoiada em bibliografia crítica, que recorda e discute, Valeria Tocco data os testemunhos em apreço: a versão de Pedro Coelho, remontando a c. 1564 , será a mais antiga ou a mais imatura; a do Cancioneiro de Luís Franco Correia, há-de situar-se c. 1572; a Lusiada de Luis de Camões, agora nuevamente reduzida por Manuel Correa Montenegro, a mais tardia, é posterior à editio princeps. Enfim, pelo confronto deste corpus com o texto impresso (base da cadeia estemática que acabará por traçar), a autora vai evidenciando dois aspectos cruciais que caracterizam a metamorfose do poema na sua fixação definitiva: o provável ajustamento a critérios censórios (religiosos e políticos), traduzido na rasura ou na mudança de passos melindrosos; o esforço de "lima" ou busca de perfeição (vislumbrável no gesto de eliminar redundâncias ou excursos, no requinte da máquina discursiva e dos subtis jogos verbais de que dependem o ritmo e a música da poesia).

Uma advertência ressalta: se é lícito aceitar como camonianas as variantes detectáveis na versão de Pedro Coelho, mais arriscada - conclui a investigadora - resulta a avaliação do testemunho de Montenegro, onde já não têm lugar aquelas variantes, mas surgem, num texto que de perto repete o da editio princeps, oitavas excedentárias, em especial nos cantos VIII e X. Valeria Tocco não duvida de que o próprio Montenegro, residente em Salamanca e corrector de profissão, interferisse na cópia realizada (explicar-se-á deste modo a predilecção por rimas castelhanizantes). Todavia - alerta -, embora entre essas estâncias figurem algumas de teor iniludivelmente apócrifo, outras não o serão, e talvez Montenegro acolhesse estrofes redigidas pelo próprio Luís Vaz na mira de estender ou desdobrar Os Lusíadas. Daí que a ensaísta termine propondo: "uma hipótese sugestiva, seria a que considerasse as três versões conhecidas numa linha de contínua evolução do texto, de aperfeiçoamento dum projecto épico que 
não se esgotaria com a versão impressa. P[edro] C[oelho], L[uís] F[ranco] C[orreia] e M[anuel] C[orreia] M[ontenegro] testemunhariam, assim, três fases da elaboração poética, que acompanharam o poeta ao longo da sua turbulenta vida, desde a juventude estudantil até à maturidade desencantada, passando pelas marcantes vicissitudes ultramarinas." (p. 105).

A entrada na oficina dos poetas é uma experiência impressionante e reveladora, e são precisamente os meandros da forja de Camões que Valeria Tocco convida a descobrir. Podemos aqui ou ali discrepar: por exemplo $(v d$. pp. 26-7), há argumentos para crer que, ao ocupar-se da estrofe 119 do canto X, com sua "matéria perigosa", Faria e Sousa teve em consideração a edição de 1584 ou a de 1591 (não as menciona abertamente, mas é à censura nelas aplicada que reage com o afã de ilibar Camões de qualquer suspeita de ataque aos jesuítas). Repare-se, porém, que este pormenor serve apenas para vincar o mérito essencial de A Lira Destemperada: o de estimular uma leitura curiosa da recepção d' Os Lusíadas, e, princi- palmente, um olhar renovado sobre o poema, na medida em que permite apreciar viragens na sua escrita e perceber ali tensões fulcrais.

Que vemos, que somos levados a pensar? Se é verdade que, na versão impressa em 1572, Camões evitou representações flagrantemente ariostescas (sem nunca apagar discretos elos entre Os Lusíadas e o Orlando Furioso), e se, privilegiando um sentido de decoro classicizante e uma aproximação a modelos historiográficos consagrados, refreou pormenores e juízos na narração da história de Portugal, ao invés, em certos (estratégicos?) momentos, acentuou efeitos contraditórios e enfatizou factores de estranhamento (escolhendo o fanfarrão Veloso como narrador das proezas dos Doze de Inglaterra; concorrendo, mercê da amplificatio do poder tirânico do amor, para que sobressaia, ainda mais ambígua, a retórica in utramque partem que encerra o canto III). Obra peregrina, pois, a que o poeta burilou ou quis erguer. E a omissão de uma tirada plena daquele cepticismo que atravessa a lírica (basta lembrar as oitavas ao desconcerto do mundo ou os sone- tos "Correm turvas as águas deste rio", "Cá nesta Babilónia, donde mana") - tirada que se espraia na versão de Pedro Coelho mas é substituída, na editio princeps, pela dura reflexão sobre os sinais dos tempos e a dissipação do ideal heróico, no termo do canto VI —, só confirma o dilema, tipicamente maneirista, que agita $O s$ Lusíadas, no insanável atrito entre a esperança e a dúvida, entre o optimismo e a desconforto, entre o encarecimento de valores épicos e a amarga expressão da descrença e inquietude de um "bicho da terra, vil e tão pequeno".

A Lira Destemperada. Sobre a tradição manuscrita de Os Lusíadas mostra que o poema camoniano continua a ser - é - um magnífico desafio. Por isso - por tudo importa que também em Portugal este livro de Valeria Tocco seja divulgado e fruído. ISABEL ALMEIDA

Caminhos da Italianística em Portugal, coordenação de Rita Marnoto, Coimbra, Instituto de Estudos Italianos da Faculdade de Letras da Universidade de Coimbra, 2004, 177 pp. [série Leonardo, 1]
Em boa hora se vê surgir, no panorama dos estudos sobre língua, literatura e cultura, uma colecção vocacionada para o estudo da italianística em Portugal, fecundo e lato campo de investigações, que convoca saberes múltiplos, mas convergentes, no esforço de captação da especificidade da nossa linguagem artística e cultural, no que ela sempre pressupõe de típica e explícita heterogeneidade. Hoje, só as iniciativas deste teor podem dinamizar produtivamente um campo de estudos, ao permitirem uma continuidade de investigação que não se esgota numa única publicação.

Não pode o investigador deixar de ser sensível, desde logo, à feliz escolha do título da colecção. De facto, o nome de série Leonardo coloca todo este projecto sob o signo da interdisciplinaridade e dos cruzamentos semióticos, atitude de investigação que esta colecção pretende acolher. A coordenação de Rita Marnoto constitui desde logo garantia de continuidade para esta série, pelo vivo interesse que, desde há largos anos, a investigadora tem vindo a demonstrar pelo estudo da literatura portu- 